\title{
Implications of dopaminergic medication withdrawal in Parkinson's disease
}

\author{
J. Koschel ${ }^{5} \cdot$ K. Ray Chaudhuri ${ }^{1} \cdot$ L. Tönges ${ }^{4} \cdot$ M. Thiel $^{5} \cdot$ V. Raeder $^{2,3} \cdot$ W. H. Jost ${ }^{5}(\mathbb{C}$
}

Received: 26 June 2021 / Accepted: 21 July 2021 / Published online: 29 July 2021

(c) The Author(s), under exclusive licence to Springer-Verlag GmbH Austria, part of Springer Nature 2021

\begin{abstract}
The trajectory of the use of dopamine replacement therapy (DRT) in Parkinson's disease (PD) is variable and doses may need to be increased, but also tapered. The plan for dose adjustment is usually done as per drug information recommendations from the licensing bodies, but there are no clear guidelines with regards to the best practice regarding the tapering off schedule given sudden dose reductions of drugs such as dopamine agonists may have serious adverse consequences. A systematic literature search was, therefore, performed to derive recommendations and the data show that there are no controlled studies or evidence-based recommendations how to taper or discontinue PD medication in a systematic manner. Most of the data were available on the dopamine agonist withdrawal syndrome (DAWS) and we found only two instructions on how to reduce pramipexole and rotigotine published by the EMA. We suggest that based on the available data, levodopa, dopamine agonists (DA), and amantadine should not be discontinued abruptly. Abrupt or sudden reduction of DA or amantadine in particular can lead to severe life-threatening withdrawal symptoms. Tapering off levodopa, COMT inhibitors, and MAO-B inhibitors may worsen motor and non-motor symptoms. Based on our clinical experience, we have proposed how to reduce PD medication and this work will form the basis of a future Delphi panel to define the recommendations in a consensus.
\end{abstract}

Keywords Parkinson's disease $\cdot$ Levodopa $\cdot$ Dopamine agonists $\cdot$ Withdrawal $\cdot$ Side effects

\section{Introduction}

Parkinson's disease (PD) is characterised by a wide range of motor and non-motor symptoms some of which remain refractory to conventional management and remains a key unmet need and challenge (LeWitt and Chaudhuri 2020). A finely balanced risk-benefit ratio is important for optimal

W. H. Jost

W.Jost@parkinson-klinik.de

1 Biomedical Research Centre, Institute of Psychiatry, Psychology and Neurosciences, King's College and Parkinson's Foundation Centre of Excellence, King's College Hospital, Denmark Hill, London, UK

2 Parkinson's Foundation Centre of Excellence, King's College Hospital, Denmark Hill, London, UK

3 Department of Neurology, Technical University Dresden, Dresden, Germany

4 Neurologische Klinik der Ruhr-Universität Bochum, Bochum, Germany

5 Parkinson-Klinik Ortenau, Kreuzbergstr. 12, 77709 Wolfach, Germany management when dealing with dopamine replacement therapy for PD and brings its own challenges in real-life use. Dopamine agonists (DA) remain a major part of clinical armamentarium for drugs used to manage PD, although in recent years, considerable issues related to "dopamine agonist phobia" (Rota et al. 2020) have emerged. In part, this is driven by the heightened awareness of the damaging and medicolegally relevant risk of impulse control disorder (ICD) and dysregulation behavioral syndromes emerging with the use of DAs. As a result, neurologists or health care professionals may sometimes reduce or discontinue a DA too quickly or abruptly in PD patients leading to dangerous complications such as dopamine agonist withdrawal syndrome (DAWS), which can be life-threatening in extreme cases (Rabinak and Nirenberg 2010; Nirenberg 2013; Ray Chaudhuri et al. 2015; Yu and Fernandez 2017;). The stoppage of oral DA abruptly can also occur in severely ill PD patients where the patient is unable to take drugs orally and have been recently highlighted in a number of patients being admitted with severe COVID-19 infection (Antonini et al. 2020). The effects can also manifest as deterioration of motor symptoms which lead to complications like 
immobilization, falls, or dysphagia with aspiration (Kofman 1984). It is therefore, important to be aware of possible complications and monitor patients carefully if discontinuing or tapering down dopaminergic medications and specifically DAs.

However, importantly, little data have been captured on the process of reducing existing dopaminergic medications and strategies to combat withdrawal symptoms. This may be based on the fact that for licensing a DA or dopamine replacement therapy (DRT), only the intake times and the changes in dosage are recorded, and as a consequence, dopaminergic drug withdrawal-related issues are only recognized if clinical problems arise such as with DAWS.

In this review, we summarize the available data based on a comprehensive literature search on the discontinuation and tapering of PD medication based on the class of dopaminergic drug used and provide a recommendation.

\section{Methods}

A systematic literature search was performed using the PubMed database by the end of March 2021. We searched for the terms 'tapering' or 'withdrawal' and 'Parkinson's disease' and the individual dopaminergic drug names. The results are shown in Table 1. We reviewed the matches and found no trials or recommendations how to taper or discontinue PD medication in detail. Based on our experience and the expected outcome if PD medication cannot be continued (e.g., because of side effects), we made a proposal on how to proceed while tapering or discontinuing PD medication.

\section{Tapering and discontinuing PD medication, available data, what has to be expected, and suggestion how to proceed}

\section{Levodopa}

Levodopa has been used as first-line medication in patients with idiopathic Parkinson's syndrome resp. Parkinson's disease (PD) for more than 50 years or when adequate symptom control is not achieved with other medication as MAO-B inhibitors, amantadine, or DA (Jost 2020). Because levodopa is effective, sometimes in a dramatic fashion to attenuate the akinetic-rigid symptoms of PD and because it has a good well studied time-honoured safety profile compared to other anti-Parkinson drugs (PD Med Collaborative Group et al. 2014), it still remains the gold standard of treatment for PD. However, Levodopa reduction (or discontinuation) can be needed in cases of levodopa over-dosing resulting in severe refractory or diphasic dyskinesias (Ray Chaudhuri et al. 2018) as well as dopamine dysregulation syndrome (DDS). Levodopa reduction is the last step in the "ladder" for reducing DRT for druginduced side effects and in cases where levodopa is to be reduced then an attempt could be made to switch to other medications, although the choice of an alternate is difficult and fraught with its own side effects like hallucinations and delirium (Ebersbach et al. 2019). In the case of a DDS, complete discontinuation of levodopa will generally not be possible, but attempts should still be made to reduce the levodopa medication as much as possible. Tapering should be monitored closely, best as in-patient, and also adapted to the patients' perception of his condition, to maintain his or her cooperation (Barbosa et al. 2018).

After deep brain stimulation (DBS) of the subthalamic nucleus (STN), the levodopa equivalent daily dose (LEDD) can usually be reduced by $30-50 \%$ for best motor outcome (Fasano et al. 2016). One study demonstrated that of 150 patients after STN-DBS, even 7\% were free from medication after 3 years (Bertholo et al. 2020).

The complete discontinuation of dopaminergic medication after STN-DBS is usually not possible, because the lack of dopamine in the limbic system and associative circuits can lead to apathy and depression (Fasano et al. 2016; Bertholo et al. 2020).

As levodopa is currently only used through enteral administration (either orally or per jejunal in the case of intrajejunal delivery), use of oral levodopa may not be possible after gastro-intestinal surgery or in cases of acute pancreatitis, whereby the medication needs to be given transdermally whenever possible (rotigotine), subcutaneous (apomorphine), or intravenous (amantadine) (Ray Chaudhuri et al. 2016).

Table 1 Results of the PubMed research

((Tapering) OR (Withdrawal)) AND (Parkinson's disease)) AND Medication

\begin{tabular}{lllllll}
\hline Medication & Levodopa & Amantadine & Pramipexole & Ropinirole & Piribedil & Rotigotine \\
\hline Articles & 446 & 43 & 46 & 33 & 4 & 13 \\
\hline Entacapone & Tolcapone & Opicapone & Rasagiline & Selegiline & Safinamide & Apomorphine \\
\hline 23 & 14 & 0 & 11 & 39 & 2 & 36
\end{tabular}




\section{Past studies of levodopa drug holidays}

In the late 1970s and 1980s, a positive and lasting effect on motor behavior after a levodopa pause (the so-called drug holidays) was repeatedly observed, although drug holidays in PD are strongly discouraged (Birkmayer and Riederer 1985), because after the abrupt discontinuation of levodopa (PD patients usually in advanced stages of the disease), a state of akinetic mutism may occur. The past studies of the 1970s were performed in hospitals with extensive nursing care because of severe health risk to the patients including increased stiffness, rigidity, tremor, and increased risk for thrombosis (Kofman 1984). As such the case numbers were small, duration of the beneficial effects of "drug holidays" and the final results were heterogeneous, and furthermore, levodopa was administered in higher doses at that time (Corona et al. 1995; Direnfeld et al. 1980; Feldman et al. 1986; Kofman 1984). The most recent study on levodopa "drug holidays" we could find was not placebo-controlled and enrolled 12 subjects who received $600 \mathrm{mg}$ of amantadine intravenously instead of levodopa during a 3-day trial. The authors reported that in spite of the abrupt change, no complications were observed (Koziorowski and Friedman 2007). When attempting to reduce the levodopa dosage, a worsening of motor performance has to be reckoned with due to its short half-life (Turjanski et al. 1993). Due to a long-duration response to levodopa, further deterioration of motor performance should be expected even after several days (7-15) (Cilia et al. 2020). Similarly, possible worsening in dysphagia might occur in advanced stages of PD (Warnecke et al. 2016). Furthermore, there are several case reports of malignant neuroleptic syndrome after discontinuation of levodopa treatment (Gibb and Griffith 1986; Gordon and Frucht 2001; Keyser and Rodnitzky 1991; Ong, Chew, and Ong 2001; Rainer, Scheinost, and Lefeber 1991; Waqas et al. 2020). Likewise, after discontinuation of dopaminergic medication including levodopa subsequent to STN-DBS, changes in personality accentuation have been documented. In a 12-month follow-up study on 73 patients after STNDBS, Lhommée et al. reported a shift from preoperative "hyperdopaminergic behavior" ("novelty seeking") with obsessive craving for sensation and pleasure, elevated mood, optimism, and hyperactivity to a trend of "hypodopaminergic" behavior with harm-avoiding tendencies, depression, pessimism, and apathy (Lhommée et al. 2017).

\section{What can be recommended?}

We have not found any studies so far on the topic of how levodopa should be reduced or rarely, stopped in detail, when necessary. A possible useful strategy would be a stepwise reduction of levodopa (for example, decreasing 50-100 mg levodopa total or $25 \mathrm{mg}$ t.i.d. every other day) utilising the levodopa equivalence dosage (LED) of the antiparkinsonian drugs that can be introduced, as shown in Table 2 (Tomlinson et al. 2010). For patients on high doses (over $1000 \mathrm{mg}$ levodopa), we recommend reducing levodopa by approximately 100 to $50 \mathrm{mg}$ per day, (for doses over $500 \mathrm{mg}$ levodopa) $25 \mathrm{mg}$ to $50 \mathrm{mg}$ per day, and for lower doses (less than $500 \mathrm{mg} / \mathrm{d}$ ) $25 \mathrm{mg}$ less every second or third day (Table 3). Such reductions have to be clinically monitored very closely and the reduction rate needs to be adjusted to clinical profile of the patient. This is particularly relevant if DDS occurs.

\section{Dopamine agonists}

The dopamine agonists (DA) pramipexole, ropinirole, and rotigotine are used in the treatment of PD as a first line or adjunctive therapy, in particular in younger patients, as stated in some, but not all, clinical guidelines (Jost 2020). Pribedil is used in some countries such as France, Romania, Poland, Latvia, Lithuania, Luxembourg, Greece, Portugal, and Germany (European Medicines Agency 2020). Rotigotine transdermal patch use in older subjects in particular is supported by observational tolerability studies (Raeder et al. 2021; Rizos et al. 2020).

Apomorphine, applied as a continuous infusion, has proven effective in advanced stages of the syndrome when motor fluctuations develop (Trenkwalder et al. 2015) and device-aided therapies are required. Reasons for reducing or discontinuing DA include switching to a therapy with levodopa/carbidopa intestinal gel (LCIG) or DBS, and especially when there are refractory side effects such as daytime somnolence with or without sudden onset of sleep events, intrusive hallucinations, peripheral edema, and ICD (Rabinak and Nirenberg 2010; Pondal et al. 2013; Yu and Fernandez 2017; Vitale et al. 2019). When apomorphine infusion pumps are operational, then discontinuation could be due to device-related technical problems, the formation of nodules at the injection sites, somnolence, nausea, and very rarely,

Table 2 Levodopa equivalent dose (LED) for antiparkinsonian drugs (Tomlinson et al. 2010)

\begin{tabular}{ll}
\hline Drug & $\begin{array}{l}\text { Total LED } \\
\text { (mg/100 mg } \\
\text { L-dopa) }\end{array}$ \\
\hline L-dopa & $100 \mathrm{mg}$ \\
Controlled release L-dopa & $133 \mathrm{mg}$ \\
Rasagiline & $1 \mathrm{mg}$ \\
Ropinirole & $5 \mathrm{mg}$ \\
Piribedil & $100 \mathrm{mg}$ \\
Rotigotin & $3,3 \mathrm{mg}$ \\
Pramipexole (salt) & $1 \mathrm{mg}$ \\
Amantadine & $100 \mathrm{mg}$ \\
Apomorphine (infusion or intermittent injections) & $10 \mathrm{mg}$ \\
\hline
\end{tabular}


Table 3 Proposal how to taper Levodopa (e.g., because of side effects)

\begin{tabular}{llll}
\hline Levodopa dose per day & Over $1000 \mathrm{mg}$ & 1000 to $500 \mathrm{mg}$ & Less than $500 \mathrm{mg}$ \\
\hline Velocity of reduction & 100 to $50 \mathrm{mg}$ less per day & 50 to $25 \mathrm{mg}$ less per day & $25 \mathrm{mg}$ les every second or third day \\
\hline
\end{tabular}

Table 4 Possible reasons for discontinuing treatment with apomorphine infusion pump (Tönges et al. 2017; Trenkwalder et al. 2015)

The formation of nodules at the injection sites

Nausea

Somnolence

Device-related technical problems

Impulse control disorder

Hallucinations

Orthostatic dysregulation

Very rarely, autoimmune hemolytic anemia

autoimmune hemolytic anemia (Table 4) (Trenkwalder et al. 2015). Raising clinician and patient awareness of potential complications to enable proactive management is important to identify and control adverse effects in a timely manner (Bhidayasiri, Garcia Ruiz, and Henriksen 2016).

Reduction and discontinuation of DA may lead to deterioration in motor and non-motor performance, which in turn necessitates the use or increasing levodopa, COMT inhibitors, or MAO-B inhibitors (Potenza et al. 2007; Voon and Fox 2007; Stamey and Jankovic 2008). Symptoms of restless legs syndrome, which have a higher incidence in PD (Andréasson et al. 2021), may well be exacerbated or even unmasked for the first time, as can akathisia as well as dopamine responsive NMS (non motor symptoms) such as depression pain, apathy, sleep disorders, etc. (Ray Chaudhuri and Schapira 2009).

In addition, DAWS may occur in 15-24\% of patients (Ray Chaudhuri et al. 2015; Yu and Fernandez 2017) exhibiting neuropsychiatric symptoms (anxiety, dysphoria, panic attacks, agitation, depression, irritability, and fatigue) and autonomic symptoms (orthostatic hypotension and perspiration) (Rabinak and Nirenberg 2010; Pondal et al. 2013). PD patients with ICD have a higher chance of developing DAWS, and both the duration and higher dosage of DA are associated with a higher risk (Stocchi et al. 2016; Yu and Fernandez 2017). DAWS can occur after a complete discontinuation of the DA or after dose reduction (Pondal et al. 2013; Ray Chaudhuri et al. 2015; Patel et al. 2017). In a study by Thobois and coworkers, 34 of 63 patients developed DAWS syndrome after abrupt discontinuation of DA following a DBS surgery (Thobois et al. 2010). The risk may also increase after sudden or abrupt discontinuation of DA when intrajejunal levodopa infusion therapy is being initiated (Solla et al. 2015).
The available data on withdrawal symptoms occurring after discontinuing an apomorphine pump are scarce compared to those discontinuing oral or transdermal DA. There are case reports describing acute lethargy after discontinuation of apomorphine pump therapy, which only improved after reintroducing of the therapy and thus could indicate a complication of acute apomorphine withdrawal (Cavallieri et al. 2019; Oliveira, Videira, and Mendes 2020).

A detailed literature search failed to reveal any studies documenting clinical and other parameters on evidencebased or expert opinion-guided strategies for discontinuing or reducing DA therapies. There are several publications recommending (when necessary) only slow/gradual reductions, but without any details on how the reduction should be done (Potenza et al. 2007; Voon and Fox 2007; Stamey and Jankovic 2008; Luchsinger, Gambhir, and DeMoss 2018). For rotigotine and pramipexole, there is a specific recommendation from the European Medicines Agency (EMA), supporting a daily reduction of rotigotine by $2 \mathrm{mg} / 24 \mathrm{~h}$ [for the restless legs syndrome (RLS), a daily reduction by $1 \mathrm{mg} / 24 \mathrm{~h}$ is recommended] (European Medicines Agency 2009b). Accordingly, the daily dose of pramipexole should be reduced by $0.75 \mathrm{mg}$ (in the salt form) daily until a daily dose of $0.75 \mathrm{mg}$ (in the salt form) is reached, after which it can be reduced by $0.375 \mathrm{mg}$ daily (European Medicines Agency 2009a).

Our personal recommendations to reduce DA are summarized in Table 5. It should be emphasized that when reducing the dose, (1) a DAWS can occur independent of the rate of the reduction and that (2) a deterioration of motor performance usually has to be compensated with levodopa with or without COMT inhibitors and regular monitoring of patients at home at this period is essential. It has to be mentioned that our proposed time-course can be slowed down significantly according to the patient response. The latter may be aided using wearable sensor based home monitoring systems. If rotigotine causes daytime sleepiness or edemas in patients suffering from RLS, it could be tried to apply the patch only during the night-time. In Table 1, the conversion factor is given for calculating the levodopa equivalence dosage according to Tomlinson and coworkers (Tomlinson et al. 2010). In a study by Contin and coworkers, the plasma concentration of pramipexole was higher (by 68\%) in patients over the age of 65 than in those younger than 65 years of age. This effect could not be observed for ropinirole or rotigotine groups (Contin et al. 2019). Therefore, reducing pramipexole in older patients should presumably be done more slowly. 
Table 5 Recommendations for dose reduction/discontinuation of dopamine agonists

Recommended rate of reduction/dis- Reduction if serious side effects continuation occur (for example: delirium)
Conversion factor for calculating the levodopa equivalent dose according to (Tomlinson et al. 2010)

\begin{tabular}{|c|c|c|c|}
\hline $\begin{array}{l}\text { Pramipexole retard (salt) } \\
(1.5 \mathrm{mg} \text { of the salt form } \\
\text { correspond to } 1.1 \mathrm{mg} \\
\text { base) }\end{array}$ & $0.375 \mathrm{mg}$ every second day & $\begin{array}{l}\text { For high doses }(>3 \mathrm{mg} / \mathrm{d}) \text { reduction } \\
\text { can start at } 0.75 \mathrm{mg} \text { (if originally } \\
4.5 \mathrm{mg} \text { then by } 1.5 \mathrm{mg}) \text {, then every } \\
\text { second day at } 0.375 \mathrm{mg}\end{array}$ & $\times 140$ \\
\hline $\begin{array}{l}\text { Pramipexole (salt) } \\
(1.5 \mathrm{mg} \text { of the salt form } \\
\text { correspond to } 1.1 \mathrm{mg} \\
\text { base) }\end{array}$ & $0.375 \mathrm{mg}$ every second day & $\begin{array}{l}\text { At high doses }(>3 \mathrm{mg} / \mathrm{d}) \text { reduction } \\
\text { can start at } 1.1 \mathrm{mg} \text {, then every } \\
\text { second day at } 0.25 \mathrm{mg}\end{array}$ & $\times 140$ \\
\hline Ropinirole & 2 mg every second day & $\begin{array}{l}\text { At high doses }(>20, \mathrm{mg} / \mathrm{d}) \text { reduc- } \\
\text { tion can start at } 8 \mathrm{mg} \text { (if origi- } \\
\text { nally }>14 \mathrm{mg} \text { then by } 6 \mathrm{mg} \text { ), then } \\
\text { by } 2 \mathrm{mg} \text { every second day }\end{array}$ & $\times 20$ \\
\hline Piribedil & $50 \mathrm{mg}$ every third day & $\begin{array}{l}\text { At } 250 \mathrm{mg} \text {, reduction can start at } \\
50 \mathrm{mg} \text {, after } 1 \text { day at } 50 \mathrm{mg} \text {, every } \\
\text { third day thereafter }\end{array}$ & $\times 1$ \\
\hline Rotigotine & $2 \mathrm{mg} / 24 \mathrm{~h}$ every second day & $\begin{array}{l}\text { For high doses }(>10 \mathrm{mg} / 24 \mathrm{~h}) \\
\text { initially reduce by } 4 \mathrm{mg} / 24 \mathrm{~h} \text {, then } \\
\text { every second day }\end{array}$ & $\times 30$ \\
\hline Apomorphine pump & Every second day reduce by $0.5 \mathrm{mg} / \mathrm{h}$ & $\begin{array}{l}\text { If technical problems necessitate an } \\
\text { abrupt discontinuation, another DA } \\
\text { (at first in low doses) can be given } \\
\text { (for example: } 4 \mathrm{mg} / 24 \mathrm{~h} \text { rotigotine, } \\
4 \mathrm{mg} \text { ropinirole, } 1.05 \mathrm{mg} \text { prami- } \\
\text { pexole or } 50 \mathrm{mg} \text { piribedil) }\end{array}$ & $\times 10$ \\
\hline
\end{tabular}

\section{Amantadine}

Amantadine is used in the treatment of early stage PD and for levodopa-induced dyskinesia (LID). The reasons for reducing or discontinuation of amantadine could be related to unremitting and troublesome peripheral edema as well as neuropsychiatric side effects, QTc prolongation, sleep disturbances, and livedo reticularis and corneal edema (Pahwa et al. 2017; Wolf et al. 2010). When amantadine is discontinued in PD patients presenting with LID, an increase in dyskinesia can be expected, as shown in the AMANDYSK study from Ory-Magne and coworkers (Ory-Magne et al. 2014) and in a study on the long-term antidyskinetic effect of amantadine from Wolf and coworkers (Wolf et al. 2010).

In the study by Wolf et al., amantadine (with an average dose of $294 \mathrm{mg}$ ) was abruptly discontinued (not recommended by us) without inducing any noteworthy adverse events, apart from one case in which there was an increase in LID. In the AMANDYSK trial, amantadine was reduced by an amount of $100 \mathrm{mg}$ every second day in 29 patients, and similarly, no significant adverse events were observed except of an aggravation of LID compared with the amantadine group. In a cross-over study with 39 PD patients with LID, of whom 17 received placebo, no adverse events were documented after 27 days of treatment apart from an increase in dyskinesia and an aggravation of off-phenomena (Sawada et al. 2010). In a similar 12-month double-blind study, elevated body temperatures $\left(38.7^{\circ}-39^{\circ}\right.$ C) occurred in 2 of 20 patients after treatment with amantadine was discontinued (Thomas et al. 2004). In these controlled studies, no significant adverse effects were reported at all, but there are several individual case studies describing an amantadine withdrawal syndrome (AWS) (Marxreiter et al. 2017; Factor et al. 1998; Miyasaki et al. 1999). In these case studies, after withdrawal or reduction of amantadine, hyperactive delirium with disorientation, restlessness, hallucinations, and argumentative tendencies occurred as well as a deterioration in motor performance which improved only after treatment with amantadine was reinstated. No alternative explanation for the delirium was evident and other therapies (such as clozapine or intravenous hydration) failed to achieve any improvement. There are a few similar case studies, reporting that amantadine withdrawal contributed to a malignant neuroleptic syndrome (Brantley et al. 2009; Fryml et al. 2017).

We recommend reducing amantadine every second or third day by $50 \mathrm{mg}$. Whereby attention has to be paid to the fact that an AWS can also develop after the discontinuation, and therefore, post-amantadine cessation monitoring is important. 


\section{MAO-B inhibitors}

The monoamine oxidase inhibitors (MAO-B inhibitors) rasagiline, selegiline, and safinamide are approved as monotherapy (RAS and SEL) or as combination therapy with levodopa (all three), and could lead to a reduction in offtime as well as an increase in on-time without disturbing dyskinesias (Binde et al. 2018; Rascol et al. 2005). In addition, there are some non-motor efficacy such as effect on pain signals with safinamide (Cattaneo et al. 2017; Geroin et al. 2020). In a meta-analysis by Binde and coworkers, the risk of terminating treatment with MAO-B inhibitors due to side effects or even the lack of efficacy was not increased compared to placebo (Binde et al. 2020). To date, we have not found any data on what may be expected after terminating treatment with rasagiline or safinamide. After termination of selegiline, only a worsening of motor performance to pre-treatment levels has been observed, but the number of subjects included in this study was marginal small (Negrotti et al. 2001). The same effect may be expected in treatments with rasagiline and safinamide.

How MAO-B inhibitors should be discontinued has not yet been studied. It is not necessary to ask this question when rasagiline is discontinued as only $1 \mathrm{mg}$ dose is used. However, because it is an MAO inhibitor with long a halflife (Finberg 2010), a slow worsening in motor behavior may be anticipated over a period of several days. If safinamide causes significant side effects, $100 \mathrm{mg} / \mathrm{d}$ may be best phased out at $50 \mathrm{mg} / \mathrm{d}$, paying attention to whether the side effect still occurs at the lower dose. To discontinue selegiline, we recommend reducing the dose by $2.5 \mathrm{mg}$ every third day. In case one MAO-B inhibitor cannot be continued (e.g., side effects), a change to some other MAO-B inhibitor may well be attempted; however, due to adverse reactions, switching to selegiline cannot be recommended here (Csoti et al. 2012).

\section{COMT inhibitors}

The Catecholamine-O-Methyltransferase inhibitors (COMT inhibitors) entacapone, tolcapone, and opicapone are given in addition to levodopa in cases of motor fluctuations. In combination with decarboxylase inhibitors, they decrease off-time and in particular reduce off-time compared to levodopa/decarboxylase inhibitors and placebo (Brooks, Sagar, and UK-Irish Entacapone Study Group 2003; Lees et al. 2007; Lees et al. 2017; Truong 2009; Ferreira et al. 2016; Yi et al. 2018). Typical reasons for discontinuation with entacapone are: dyskinesia, diarrhea, discolouration of the urine, nausea, and insufficient effect (Parashos et al. 2004).
Tolcapone is rarely used apart from named patient basis owing to worldwide alert for fatal hepatic failure in the 1990s (Lees et al. 2007), and where it is still used, discontinuation of tolcapone is indicated in the event of dyskinesia, diarrhea, nausea, dizziness, and particularly in cases of elevated levels of hepatic transaminases. Our research so far has not found any studies on to how COMT inhibitors should be discontinued or phased out. Discontinuation of entacapone leads to an increase in off-time and a decrease in ontime (Brooks, Sagar, and UK-Irish Entacapone Study Group 2003). This effect may also be expected for tolcapone (Lees 2008) and opicapone. However, as far as we have found in the literature, other adverse effects after terminating of COMT inhibitors in the nature of a withdrawal syndrome have not been observed yet.

Considering the likely increase in motor fluctuations after incompatibility of a COMT inhibitor after its discontinuation, we recommend switching to another COMT inhibitor the very next day. In the event that diarrhea as well as urine discolouration may occur with entacapone or tolcapone treatment, switching to opicapone may be considered. Opicapone is a third-generation COMT inhibitor and has a long half-life (Greenwood et al. 2021). As such if opicapone withdrawal is considered, then switching to entacapone (where opicapone was used first line) or an alternative enzyme inhibitor may be required and deterioration in off-time may occur over several days.

\section{Conclusions}

In this review, we searched for available evidence to guide PD medication management when tapering or discontinuing becomes necessary, for example because of side effects. We found that no study addressed the management how to reduce antiparkinsonian drugs, except two instructions on how to reduce Mirapexin ${ }^{\circledR}$ (pramipexole) and Neupro ${ }^{\circledR}$ (rotigotine) published by the EMA, without references. To avoid hypodopaminergic states with depression and apathy, motor deterioration with consecutive complications like falls and withdrawals syndromes (e.g., DAWS), PD medication has to be reduced carefully and patients have to be monitored closely. The proposals how to reduce PD medication in this work is based on our experience and they might have to be adjusted in case of adverse events, because reaction to medication change in PD varies from patient to patient and depends on the progression of the disease. The specific suggestion for each medication is shown in the text, and the proposal for a common pathway is shown in Fig. 1. Further research is required to improve medication management when PD medication has to be reduced to maintain a proper life quality of the patients. 


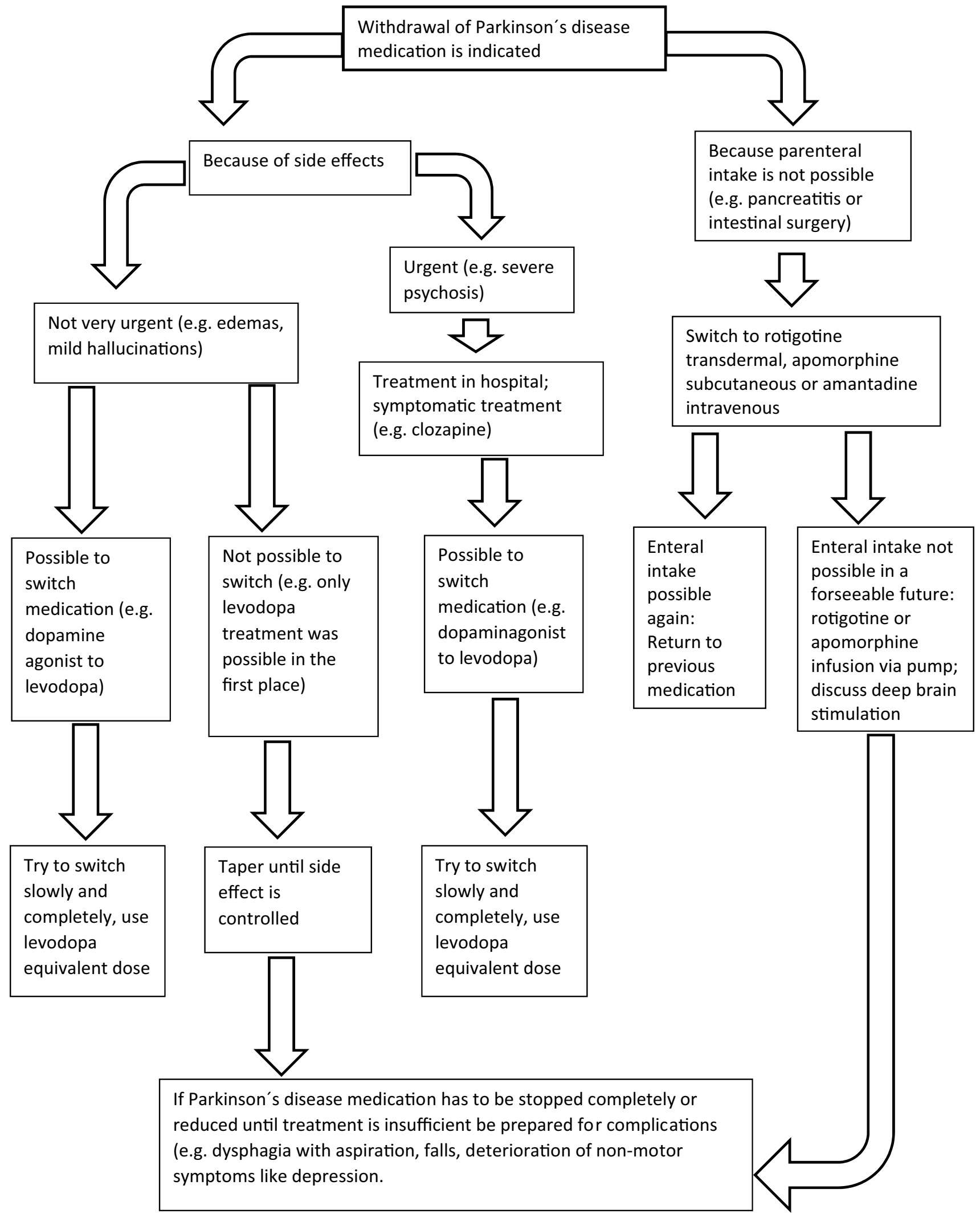

Fig. 1 Proposal for a common pathway how to reduce PD medication 
Acknowledgements Boto Balond, Gerhard Bonitz, David Emmans, and Ziad Salhani.

\section{Declarations}

Conflict of interest JK: reports advisory board for Abbvie, honoraria for speaker from Desitin. MT: no conflict of interest. KRC: reports advisory board for AbbVie, UCB, GKC, Bial, Cynapsus, Novartis, Lobsor, Stada, Medtronic, Zambon, Profile, Sunovion, Roche, Theravance, Scion, Britannia; honoraria for lectures from AbbVie, Britannia, UCB, Mundipharma, Zambon, Novartis, Boehringer Ingelheim; Grants (Investigator Initiated) from Britannia Pharmaceuticals, AbbVie, UCB, GKC, Bial; academic grants from EU, IMI EU, Horizon 2020, Parkinson's UK, NIHR, PDNMG, EU (Horizon 2020), Kirby Laing Foundation, NPF, MRC, Wellcome Trust. VR: has received funding for educational articles from Britannia pharmaceuticals. WHJ is speaker and advisor for: Abbvie, Bial, Desitin, Ipsen, Merz, Stada, $\mathrm{UCB}$, and Zambon.

\section{References}

Antonini A, Leta V, Teo J, Ray Chaudhuri K (2020) Outcome of Parkinson's disease patients affected by COVID-19. Movem Disord 35(6):905-908. https://doi.org/10.1002/mds.28104

Barbosa P, Djamshidian A, Lees AJ, Warner TT (2018) The outcome of dopamine dysregulation syndrome in Parkinson's disease: a retrospective postmortem study. Movement Disorders Clinical Practice 5(5):519-522. https://doi.org/10.1002/mdc3.12671

Bertholo AP, França C, Fiorini WS, Barbosa ER, Cury RG (2020) Medical management after subthalamic stimulation in parkinson's disease: a phenotype perspective. Arq Neuropsiquiatr 78(4):230 237. https://doi.org/10.1590/0004-282X20190188

Bhidayasiri R, Garcia PJ, Ruiz, and Tove Henriksen (2016) Practical management of adverse events related to apomorphine therapy. Parkinsonism Relat Disord 33 Suppl 1(December):S42-S48. https://doi.org/10.1016/j.parkreldis.2016.11.017

Binde CD, Tvete IF, Gåsemyr J, Natvig B, Klemp M (2018) A multiple treatment comparison meta-analysis of monoamine oxidase type B inhibitors for Parkinson's disease. Br J Clin Pharmacol 84(9):1917-1927. https://doi.org/10.1111/bcp.13651

Binde CD, Tvete IF, Gåsemyr JI, Natvig B, Klemp M (2020) Comparative effectiveness of dopamine agonists and monoamine oxidase type-b inhibitors for parkinson's disease: a multiple treatment comparison meta-analysis. Eur J Clin Pharmacol 76(12):17311743. https://doi.org/10.1007/s00228-020-02961-6

Birkmayer W, Riederer P (1985) Die Parkinson-Krankheit: Biochemie, Klinik, Therapie, 2nd edn. Springer-Verlag, Wien. https://doi.org/ 10.1007/978-3-7091-2262-4

Brantley EJ, Cohn JV, Babu KM (2009) Case files of the program in medical toxicology at Brown University: amantadine withdrawal and the neuroleptic malignant syndrome. J Med Toxicol 5(2):9298. https://doi.org/10.1007/BF03161096

Brooks, D. J., H. Sagar, and UK-Irish Entacapone Study Group (2003) Entacapone is beneficial in both fluctuating and non-fluctuating patients with parkinson's disease: a randomised, placebo controlled, double blind, six month study. J Neurol Neurosurg Psychiatry 74(8):1071-1079. https://doi.org/10.1136/jnnp.74.8.1071

Cattaneo C, Barone P, Bonizzoni E, Sardina M (2017) Effects of safinamide on pain in fluctuating Parkinson's disease patients: a posthoc analysis. J Parkinson's Dis 7(1):95-101. https://doi.org/10. 3233/JPD-160911

Cavallieri F, Fraix V, Meoni S, Krack P, Moro E, Castrioto A (2019) Acute lethargy after abrupt apomorphine withdrawal in
Parkinson's disease. J Neurol Sci 404(September):44-46. https:// doi.org/10.1016/j.jns.2019.07.011

Chaudhuri KR, Schapira AHV (2009) Non-motor symptoms of parkinson's disease: dopaminergic pathophysiology and treatment. Lancet Neurol 8(5):464-474. https://doi.org/10.1016/S14744422(09)70068-7

Chaudhuri KR, Todorova A, Nirenberg MJ, Parry M, Martin A, Martinez-Martin P, Rizos A et al (2015) A pilot prospective, multicenter observational study of dopamine agonist withdrawal syndrome in Parkinson's disease. Movem Disord Clin Pract 2(2):170-174. https://doi.org/10.1002/mdc3.12141

Cilia R, Cereda E, Akpalu A, Sarfo FS, Cham M, Laryea R, Obese $\mathrm{V}$ et al (2020) Natural history of motor symptoms in Parkinson's disease and the long-duration response to levodopa. Brain 143(8):2490-2501. https://doi.org/10.1093/brain/awaa181

Contin M, Lopane G, Mohamed S, Calandra-Buonaura G, Capellari S, De Massis P, Nassetti S et al (2019) Clinical pharmacokinetics of pramipexole, ropinirole and rotigotine in patients with Parkinson's disease. Parkinsonism Relat Disord 61:111-117. https://doi.org/ 10.1016/j.parkreldis.2018.11.007

Corona T, Rivera C, Otero E, Stopp L (1995) A longitudinal study of the effects of an 1-dopa drug holiday on the course of Parkinson's disease. Clin Neuropharmacol 18(4):325-332. https://doi.org/10. 1097/00002826-199508000-00004

Ilona C, Storch A, Müller W, Jost WH (2012) Drug interactions with selegiline versus rasagiline. Basal Ganglia, Monoamine oxidase B Inhibitors 2(4):S27-S31. https://doi.org/10.1016/j.baga.2012. 06.003

Direnfeld LK, Feldman RG, Alexander MP, Kelly-Hayes M (1980) Is L-DOPA drug holiday useful? Neurology 30(7 Pt 1):785-788. https://doi.org/10.1212/wnl.30.7.785

Ebersbach G, Ip CW, Klebe S, Koschel J, Lorenzl S, Schrader C, Winkler C, Franke C (2019) Management of delirium in Parkinson's disease. J Neural Transm 126(7):905-912. https://doi.org/10. 1007/s00702-019-01980-7

European Medicines Agency (2009a) 'Mirapexin: EPAR- Product Information'. European Medicines Agency. https://www.ema. europa.eu/documents/product-information/mirapexin-epar-produ ct-information_en.pdf.

European Medicines Agency (2009b). 'Neupro: Epar-Product Information'. European Medicines Agency. https://www.ema.europa. eu/en/documents/product-information/neupro-epar-product-infor mation_en.pdf.

European Medicines Agency (2009c). 'List of Nationally Authorised Medicinal Products Active Substance: Piribedil'. https://www. ema.europa.eu/en/documents/psusa/piribedil-list-nationally-autho rised-medicinal-products-psusa/00002436/202003_en.pdf.

Factor SA, Molho ES, Brown DL (1998) Acute delirium after withdrawal of amantadine in Parkinson's disease. Neurology 50(5):1456-1458. https://doi.org/10.1212/wnl.50.5.1456

Fasano A, Appel-Cresswell S, Jog M, Zurowkski M, Duff-Canning S, Cohn M, Picillo M, Honey CR, Panisset M, Munhoz RP (2016) Medical management of parkinson's disease after initiation of deep brain stimulation. Canad J Neurol Sci 43(5):626-34. https:// doi.org/10.1017/cjn.2016.274

Feldman RG, Kaye JA, Lannon MC (1986) Parkinson's disease: followup after "drug holiday." J Clin Pharmacol 26(8):662-667. https:// doi.org/10.1002/j.1552-4604.1986.tb02969.x

Ferreira JJ, Lees A, Rocha J-F, Poewe W, Rascol O, Soares-da-Silva P, Bi-Park 1 investigators (2016) Opicapone as an adjunct to levodopa in patients with parkinson's disease and end-of-dose motor fluctuations: a randomised, double-blind, controlled trial. Lancet Neurol 15(2):154-165. https://doi.org/10.1016/S1474-4422(15) 00336-1

Finberg JPM (2010) Pharmacology of rasagiline, a new MAO-B inhibitor drug for the treatment of parkinson's disease with 
neuroprotective potential. Rambam Maimonides Med J. https:// doi.org/10.5041/RMMJ.10003

Fryml LD, Williams KR, Pelic CG, Fox J, Sahlem G, Robert S, Revuelta GJ, Short EB (2017) The role of amantadine withdrawal in 3 cases of treatment-refractory altered mental status. J Psychiatr Pract 23(3):191-199. https://doi.org/10.1097/PRA.0000000000 000237

Christian G, Diico IA, Squintani G, Segatti A, Bovi T, Tinazzi M (2020) Effects of safinamide on pain in Parkinson's disease with motor fluctuations: an exploratory study'. J Neural Transm 127(8):1143-52. https://doi.org/10.1007/s00702-020-02218-7

Gibb WR, Griffith DN (1986) Levodopa withdrawal syndrome identical to neuroleptic malignant syndrome. Postgrad Med J 62(723):5960. https://doi.org/10.1136/pgmj.62.723.59

Gordon PH, Frucht SJ (2001) Neuroleptic malignant syndrome in advanced Parkinson's disease. Movem Disord 16(5):960-962. https://doi.org/10.1002/mds.1166

Greenwood J, Pham H, Rey J (2021) Opicapone: a third generation COMT inhibitor. Clin Parkinsonism Relat Disord 4(January):100083. https://doi.org/10.1016/j.prdoa.2020.100083

Jost, W. H. 2020. Therapie des idiopathischen Parkinson-Syndroms. 11., neubearb. Auflage 2020. UNI-MED Science, Bremen.

Keyser DL, Rodnitzky RL (1991) Neuroleptic malignant syndrome in parkinson's disease after withdrawal or alteration of dopaminergic therapy. Arch Intern Med 151(4):794-796

Kofman OS (1984) ‘Are levodopa “drug holidays” justified?' Canad J Neurol Sci 11(1 Suppl):206-209. https://doi.org/10.1017/s0317 167100046424

Koziorowski D, Friedman A (2007) Levodopa "drug holiday" with amantadine infusions as a treatment of complications in parkinson's disease. Movem Disord 22(7):1033-1036. https://doi.org/ 10.1002/mds. 21448

Lees AJ, Ratziu V, Tolosa E, Oertel WH (2007) Safety and tolerability of adjunctive tolcapone treatment in patients with early Parkinson's disease. J Neurol Neurosurg Psychiatry 78(9):944-948. https://doi.org/10.1136/jnnp.2006.097154

Lees AJ (2008) Evidence-based efficacy comparison of tolcapone and entacapone as adjunctive therapy in parkinson's disease. CNS Neurosci Ther 14(1):83-93. https://doi.org/10.1111/j.1527-3458. 2007.00035.x

Lees, Andrew J., Joaquim Ferreira, Olivier Rascol, Werner Poewe, José-Francisco Rocha, Michelle McCrory, Patricio Soares-daSilva, and BIPARK-2 Study Investigators (2017) Opicapone as adjunct to levodopa therapy in patients with parkinson disease and motor fluctuations: a randomized clinical trial. JAMA Neurol 74(2):197-206. https://doi.org/10.1001/jamaneurol.2016.4703

LeWitt PA, Ray Chaudhuri K (2020) Unmet needs in Parkinson disease: motor and non-motor. Parkinsonism Relat Disord 80(November):S7-12. https://doi.org/10.1016/j.parkreldis.2020. 09.024

Lhommée E, Boyer F, Wack M, Pélissier P, Klinger H, Schmitt E, Bichon A et al (2017) Personality, dopamine, and parkinson's disease: insights from subthalamic stimulation. Mov Disord 32(8):1191-1200. https://doi.org/10.1002/mds.27065

Walter TL, Gambhir N, DeMoss D (2018) Prevention of dopamine dysregulation syndrome in Parkinson's disease: a case report. Primary Care Compan CNS Disord. https://doi.org/10.4088/PCC.17102127

Marxreiter F, Winkler J, Uhl M, Madžar D (2017) A case report of severe delirium after amantadine withdrawal. Case Rep Neurol 9(1):44-48. https://doi.org/10.1159/000460814

Miyasaki JM, Grimes D, Lang AE (1999) Acute delirium after withdrawal of amantadine in Parkinson's disease. Neurology 52(8):1720-1721. https://doi.org/10.1212/wnl.52.8.1717-d

Negrotti A, Bizzarri G, Calzetti S (2001) Long-term persistence of symptomatic effect of selegiline in parkinson's disease, a two-months placebo-controlled withdrawal study. J Neural Transm 108(2):215-219. https://doi.org/10.1007/s007020170089

Nirenberg MJ (2013) Dopamine agonist withdrawal syndrome: implications for patient care. Drugs Aging 30(8):587-592. https://doi. org/10.1007/s40266-013-0090-z

Oliveira V, Gonçalo V, Alexandre M (2020) Loss of awareness after continuous apomorphine infusion withdrawal in Parkinson's disease. Canad J Neurol Sci 47(4):576-77. https://doi.org/10.1017/ cjn. 2020.43

Ong KC, Chew EL, Ong YY (2001) Neuroleptic malignant syndrome without neuroleptics. Singapore Med J 42(2):85-88

Ory-Magne F, Corvol J-C, Azulay J-P, Bonnet A-M, Brefel-Courbon C, Damier P, Dellapina E et al (2014) Withdrawing amantadine in dyskinetic patients with Parkinson disease: the AMANDYSK trial. Neurology 82(4):300-307. https://doi.org/10.1212/WNL. 0000000000000050

Pahwa R, Tanner CM, Hauser RA, Isaacson SH, Nausieda PA, Truong DD, Agarwal P et al (2017) ADS-5102 (Amantadine) extendedrelease capsules for levodopa-induced dyskinesia in Parkinson disease (EASE LID study): a randomized clinical trial. JAMA Neurol 74(8):941-949. https://doi.org/10.1001/jamaneurol.2017.0943

Parashos SA, Wielinski CL, Kern JA (2004) Frequency, reasons, and risk factors of entacapone discontinuation in Parkinson disease. Clin Neuropharmacol 27(3):119-123

Patel S, Garcia X, Mohammad ME, Xin Xin Yu, Vlastaris K, O'Donnell K, Sutton K, Fernandez HH (2017) Dopamine agonist withdrawal syndrome (DAWS) in a tertiary parkinson disease treatment center. J Neurol Sci 379(August):308-311. https://doi. org/10.1016/j.jns.2017.06.022

PD Med Collaborative Group, Gray R, Ives N, Rick C, Patel S, Gray A, Jenkinson C et al (2014) Long-term effectiveness of dopamine agonists and monoamine oxidase $b$ inhibitors compared with levodopa as initial treatment for parkinson's disease (PD MED): a large, open-label, pragmatic randomised trial. Lancet (london, England) 384(9949):1196-1205. https://doi.org/10.1016/S01406736(14)60683-8

Pondal M, Marras C, Miyasaki J, Moro E, Armstrong MJ, Strafella AP, Shah BB et al (2013) Clinical features of dopamine agonist withdrawal syndrome in a movement disorders clinic. J Neurol Neurosurg Psychiatry 84(2):130-135. https://doi.org/10.1136/ jnnp-2012-302684

Potenza MN, Voon V, Weintraub D (2007) Drug insight: impulse control disorders and dopamine therapies in parkinson's disease. Nat Clin Pract Neurol 3(12):664-672. https://doi.org/10.1038/ncpne uro0680

Rabinak CA, Nirenberg MJ (2010) Dopamine agonist withdrawal syndrome in Parkinson disease. Arch Neurol 67(1):58-63. https://doi. org/10.1001/archneurol.2009.294

Raeder V, Boura I, Leta V, Jenner P, Reichmann H, Trenkwalder C, Klingelhoefer L, Ray Chaudhuri K (2021) Rotigotine transdermal patch for motor and non-motor Parkinson's disease: a review of 12 years. Clin Exp CNS Drugs 35(2):215-231. https://doi.org/10. 1007/s40263-020-00788-4

Rainer C, Scheinost NA, Lefeber EJ (1991) Neuroleptic malignant syndrome when levodopa withdrawal is the cause. Postgrad Med 89(5):175-78. https://doi.org/10.1080/00325481.1991.11700900

Rascol O, Brooks DJ, Melamed E, Oertel W, Poewe W, Stocchi F, Tolosa E (2005) Rasagiline as an adjunct to levodopa in patients with Parkinson's disease and motor fluctuations (largo, lasting effect in adjunct therapy with rasagiline given once daily, study): a randomised, double-blind, parallel-group trial. The Lancet 365(9463):947-954. https://doi.org/10.1016/S0140-6736(05) 71083-7

Ray Chaudhuri K, Poewe W, Brooks D (2018) Motor and nonmotor complications of levodopa: phenomenology, risk factors, and 
imaging features. Movem Disord 33(6):909-919. https://doi.org/ $10.1002 / \mathrm{mds} .27386$

Ray Chaudhuri K, Qamar MA, Rajah T, Loehrer P, Sauerbier A, Odin P, Jenner P (2016) Non-oral dopaminergic therapies for parkinson's disease: current treatments and the future. NPJ Parkinson's Disease 2(1):1-7. https://doi.org/10.1038/npjparkd.2016.23

Rizos, A., A. Sauerbier, C. Falup-Pecurariu, P. Odin, A. Antonini, P. Martinez-Martin, B. Kessel, et al. 2020. 'Tolerability of NonErgot Oral and Transdermal Dopamine Agonists in Younger and Older Parkinson's Disease Patients: An European Multicentre Survey'. Journal of Neural Transmission (Vienna, Austria: 1996) 127 (6): 875-79. https://doi.org/10.1007/s00702-020-02168-0.

Rota S, Boura I, Batzu L, Titova N, Jenner P, Falup-Pecurariu C, Ray Chaudhuri K (2020) "Dopamine Agonist Phobia" in Parkinson's Disease: When Does It Matter? Implications for Non-Motor Symptoms and Personalized Medicine. Expert Rev Neurother 20(9):953-965. https://doi.org/10.1080/14737175.2020.1806059

Sawada, Hideyuki, Tomoko Oeda, Sadako Kuno, Masahiro Nomoto, Kenji Yamamoto, Mitsutoshi Yamamoto, Kinya Hisanaga, Takashi Kawamura, and Amantadine Study Group (2010) Amantadine for dyskinesias in parkinson's disease: a randomized controlled trial. PLoS ONE 5(12):e15298. https://doi.org/10.1371/journal.pone. 0015298

Solla P, Fasano A, Cannas A, Mulas CS, Marrosu MG, Lang AE, Marrosu F (2015) Dopamine agonist withdrawal syndrome (DAWS) symptoms in parkinson's disease patients treated with levodopacarbidopa intestinal gel infusion. Parkinsonism Relat Disord 21(8):968-971. https://doi.org/10.1016/j.parkreldis.2015.05.018

Stamey W, Jankovic J (2008) Impulse control disorders and pathological gambling in patients with Parkinson disease. Neurologist 14(2):89-99. https://doi.org/10.1097/NRL.0b013e31816606a7

Stocchi F, Torti M, Fossati C (2016) Advances in Dopamine Receptor Agonists for the Treatment of Parkinson's Disease. Expert Opin Pharmacother 17(14):1889-1902. https://doi.org/10.1080/14656 566.2016.1219337

Thobois, Stéphane, Claire Ardouin, Eugénie Lhommée, Hélène Klinger, Christelle Lagrange, Jing Xie, Valérie Fraix, et al. 2010. 'Non-Motor Dopamine Withdrawal Syndrome after Surgery for Parkinson's Disease: Predictors and Underlying Mesolimbic Denervation'. Brain: A Journal of Neurology 133 (Pt 4): 1111-27. https://doi.org/10.1093/brain/awq032.

Thomas A, Iacono D, Luciano AL, Armellino K, Di Iorio A, Onofrj M (2004) Duration of amantadine benefit on dyskinesia of severe Parkinson's disease. J Neurol Neurosurg Psychiatry 75(1):141-143

Tomlinson CL, Stowe R, Patel S, Rick C, Gray R, Clarke CE (2010) Systematic review of levodopa dose equivalency reporting in parkinson's disease. Movem Disord 25(15):2649-2653. https://doi. org/10.1002/mds.23429

Tönges, Lars, Andrés Ceballos-Baumann, Holger Honig, Alexander Storch, and Wolfgang H. Jost. 2017. 'Praktische Anwendung der kontinuierlichen Apomorphin-Pumpentherapie'. Fortschritte der Neurologie · Psychiatrie 85 (9): 516-35. https://doi.org/10. 1055/s-0043-110095.
Trenkwalder C, Ray Chaudhuri K, García PJ, Ruiz PL, Katzenschlager R, Sixel-Döring F, Henriksen T et al (2015) Expert consensus group report on the use of apomorphine in the treatment of Parkinson's disease-clinical practice recommendations. Parkinsonism Relat Disord 21(9):1023-1030. https://doi.org/10.1016/j.parkr eldis.2015.06.012

Truong DD (2009) Tolcapone: review of Its pharmacology and use as adjunctive therapy in patients with parkinson's disease. Clin Interv Aging 4:109-113

Turjanski N, Fernandez W, Lees AJ (1993) The effects of acute levodopa withdrawal on motor performance and dopaminergic receptor sensitivity in patients with Parkinson's Disease. J Neurol Neurosurg Psychiatry 56(7):771-775. https://doi.org/10.1136/ jnnp.56.7.771

Vitale C, Amboni M, Erro R, Picillo M, Pellecchia MT, Barone P, Trojano L, Santangelo G (2019) Parkinson's disease management and impulse control disorders: current state and future perspectives. Expert Rev Neurother 19(6):495-508. https://doi.org/10. 1080/14737175.2019.1620603

Voon V, Fox SH (2007) Medication-related impulse control and repetitive behaviors in parkinson disease. Arch Neurol 64(8):10891096. https://doi.org/10.1001/archneur.64.8.1089

Waqas, S., M. Talty, S. O'Keeffe, J. Flood, and A. M. Doherty. 2020. 'There is more to this fever than meets the eye: a case of neuroleptic malignant-like syndrome (NMLS) secondary to withdrawal of procyclidine and L-Dopa on a background of long-standing flupenthixol depot use'. Irish Journal of Psychological Medicine, April, 1-4. https://doi.org/10.1017/ipm.2020.14.

Warnecke T, Suttrup I, Schröder JB, Osada N, Oelenberg S, Hamacher C, Suntrup S, Dziewas R (2016) Levodopa responsiveness of dysphagia in advanced parkinson's disease and reliability testing of the fees-levodopa-test. Parkinsonism Relat Disord 28:100-106. https://doi.org/10.1016/j.parkreldis.2016.04.034

Wolf E, Seppi K, Katzenschlager R, Hochschorner G, Ransmayr G, Schwingenschuh P, Ott E et al (2010) Long-term antidyskinetic efficacy of amantadine in parkinson's disease. Mov Disord 25(10):1357-1363. https://doi.org/10.1002/mds.23034

Yi Z-M, Qiu T-T, Zhang Y, Liu Na, Zhai S-D (2018) Levodopa/carbidopa/entacapone versus levodopa/dopa-decarboxyiase inhibitor for the treatment of parkinson's disease: systematic review, meta-analysis, and economic evaluation. Ther Clin Risk Manag 14(April):709-719. https://doi.org/10.2147/TCRM.S163190

Yu XX, Fernandez HH (2017) Dopamine agonist withdrawal syndrome: a comprehensive review. J Neurol Sci 374(March):53-55. https://doi.org/10.1016/j.jns.2016.12.070

Publisher's Note Springer Nature remains neutral with regard to jurisdictional claims in published maps and institutional affiliations. 